\title{
COMPARISON OF SENSITIVITY OF ANALYTICAL METHODS FOR SAMPLES INJECTION IN THE DETECTION OF COMPOUNDS WITH FLAVOURING POTENTIAL OF WINES
}

\author{
Rodica Sturza ${ }^{1}$, Constantin Sîrghi ${ }^{1}$, Mariana Vrîncean ${ }^{1}$, Susanne Böhme ${ }^{2}$ \\ Technical University of Moldova ${ }^{I}$, Shimadzu Europa $\mathrm{GmbH}^{2}$ \\ E-mail:utm.marianav@gmail.com
}

\begin{abstract}
The study has been focused on the comparative analysis of various analytical techniques for the injection of samples applied to detect the additives with flavouring potential that are used to obtain illicitly the "Muscat" and "Isabela" wines, by implementing the GC/MS method with injection of liquid samples directly into the capillary column, using the "Head-space" method and the solid phase microextraction (SPME).
\end{abstract}

Keywords: GC/MS, Head-space, SPME, Wine and Flavours

\section{Introduction}

The wine aroma is a basic element of the quality of wine obtained from grapes. Aroma compounds are most closely associated with the volatile fraction of food [1].

The study of the volatile fraction in enological products has become necessary and is more than sufficiently justified, considering these compounds make a major contribution to the consumer's overall perception of the quality of particular food and drink products. In fact, these complex volatile compounds largely determine the acceptance or rejection of many products by the consumer. In addition, product characteristics known as "off-flavours", caused by the presence of volatiles that give rise to disagreeable odour and flavours, often imply microbial contamination; therefore the study of volatiles becomes part of the larger subject of food safety [2].

In other words, the wine flavour results from a harmonious compound of several chemicals having different origin and structure. The main focus is on the terpenoids substances that are capable to release smelling volatile substances (terpenes) through hydrolysis. The methoxypyrazines, some compounds with thiol functions, phenolic acids also belong to this category. Through decarboxylation they form the aldehydes, alcohols, and later esters, which can have the flavour of flowers or fruits [3].

The determination of the volatile fraction is normally performed by gas chromatography (GC), a technique which in recent years has made great advances.

Given that SPME is very appropriate for application in the field of volatile compounds, this technique is being widely used for the characterization of wines [4]. Bonino and others [5] utilized HS-SPME for the extraction of aroma compounds characterizing a Piedmont wine (Ruché) derived from a non-aromatic wine. The most aromatic monoterpenes, are in the form of monoterpenic alcohols, namely linalool, $\alpha$-terpineol, nerol, geraniol, citronellol, hotrienol (HO-trienol, (5E)-3,5-dimethylocta-1,5,7-trien-3-ol), which express the rose flavour [6], [7]. The citronellol and linalool are the most aromatic, playing an important role in the formation of Muscat varieties flavour, where their concentration is higher the perception threshold [8].

In order to improve the gustatory and olfactory properties of grape wines or in order to give them certain characteristics, the wine aromatisation often is carried out illegally by adding different flavoured substances both of plant and synthetic origin. The usage of any type of flavoured elements, of synthetic origin included, for the natural wine production is prohibited by the EU and RM legislation [9].

The information concerning the toxic action of ethanol in combination with synthetic aromatizing compounds often does not have a relevant character. While carrying out the research in the field of alcohol products toxicology and detection of compounds which are harmful or potentially dangerous for the human body, the role of the control over such unauthorized applications of additives in the process of wine making increases.

The objective of this research was to compare the efficiency of various analytical techniques for the injection of samples used to detect the additives with flavouring potential that are utilised for the illicit obtaining of "Muscat" and "Isabel" wines on the basis of raw material wine with neutral aromatic potential.

\section{Materials and Methods}

For the analysis, the raw material wine of „Mixture of European white varieties” and „Mixture of European red varieties" type were used, to which have been added naturally identical aromatizers of "Muscat" (white wine) and "Isabel" (red wine) type from commerce, in the recommended amount (1:10000). Subsequently, the comparative analysis of the composition of raw material wine and of the "variety" wine has been carried out using the GC/MS method by injecting liquid samples directly into the capillary column, the „head-space” (HS) method and the solid phase microextraction (SPME). 


\section{Experimental conditions:}

All tests have been carried out using the Shimadzu GC system coupled with a single quadrupole massspectrometer GCMS-QP2010 Plus equipped with the three-dimensional automated system for the injection of samples AOC-5000 (GCMS-QP2010 PlusxAOC-5000) (figure 1a).

The experimental conditions for the analysis of the injection of liquid samples directly into the capillary column are presented in figure $1 \mathrm{~b}$; of the injection of samples using the HS method - in figure 1c; of the injection of samples using the SPME method - in figure 1d.
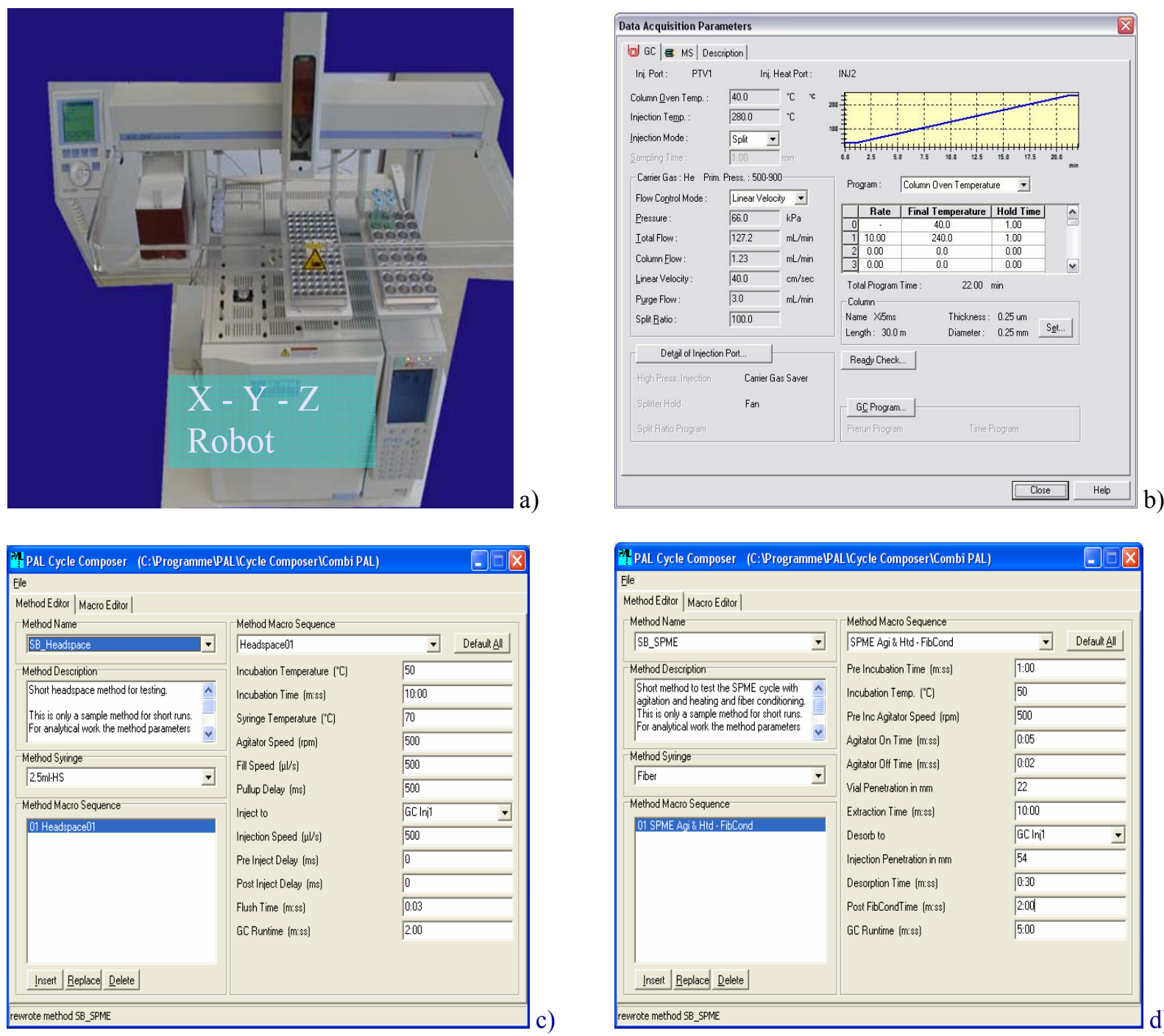

Figure 1. Three-dimensional automated system for the injection of samples AOC-5000 (GCMS-QP2010xAOC-5000) (a) and the experimental conditions for the analysis of the injection of liquid samples directly into the capillary column (b); using the „head-space” method (c) and using the solid phase microextraction (SPME) (d)

In the case of injection of samples by the HS and SPME methods, the $20 \mathrm{ml}$ vials have been used, in which 10 $\mathrm{ml}$ of sample and $4 \mathrm{~g}$ of $\mathrm{NaCl}$ were administered. For the solid phase microextraction (SPME), the 100 $\mu \mathrm{m}$ CarboxenPDMS fibre was used, which provides the extraction of volatile and semi-volatile compounds on a concentration range from tenths of ppb up to tens of ppm [10].

For the identification, the general library of NIST-5 mass spectra and the FFNSC 1.3, a library which was specially developed for flavours and fragrances (available from Shimadzu Europa GmbH) were used. The accuracy of displacement has been verified according to the library of Covatz retention indices (MLRI). The analysis of the experimental data was carried out with the GC/MS Solution software (Shimadzu), which contains the SCAN/SIM options (Fast Automated Scan/SIM Type (FASST); creation of automatic SIM (Scan/SIM) table (COAST). 


\section{Results and Discussions}

The comparative analysis of the composition of raw material wine of "Mixture of white European varieties" and "variety" types, by adding naturally identical aromatizers of "Muscat" type, carried out using the GC/MS method with the injection of liquid samples directly into the capillary column, indicates the presence of unessential differences (figure 2).

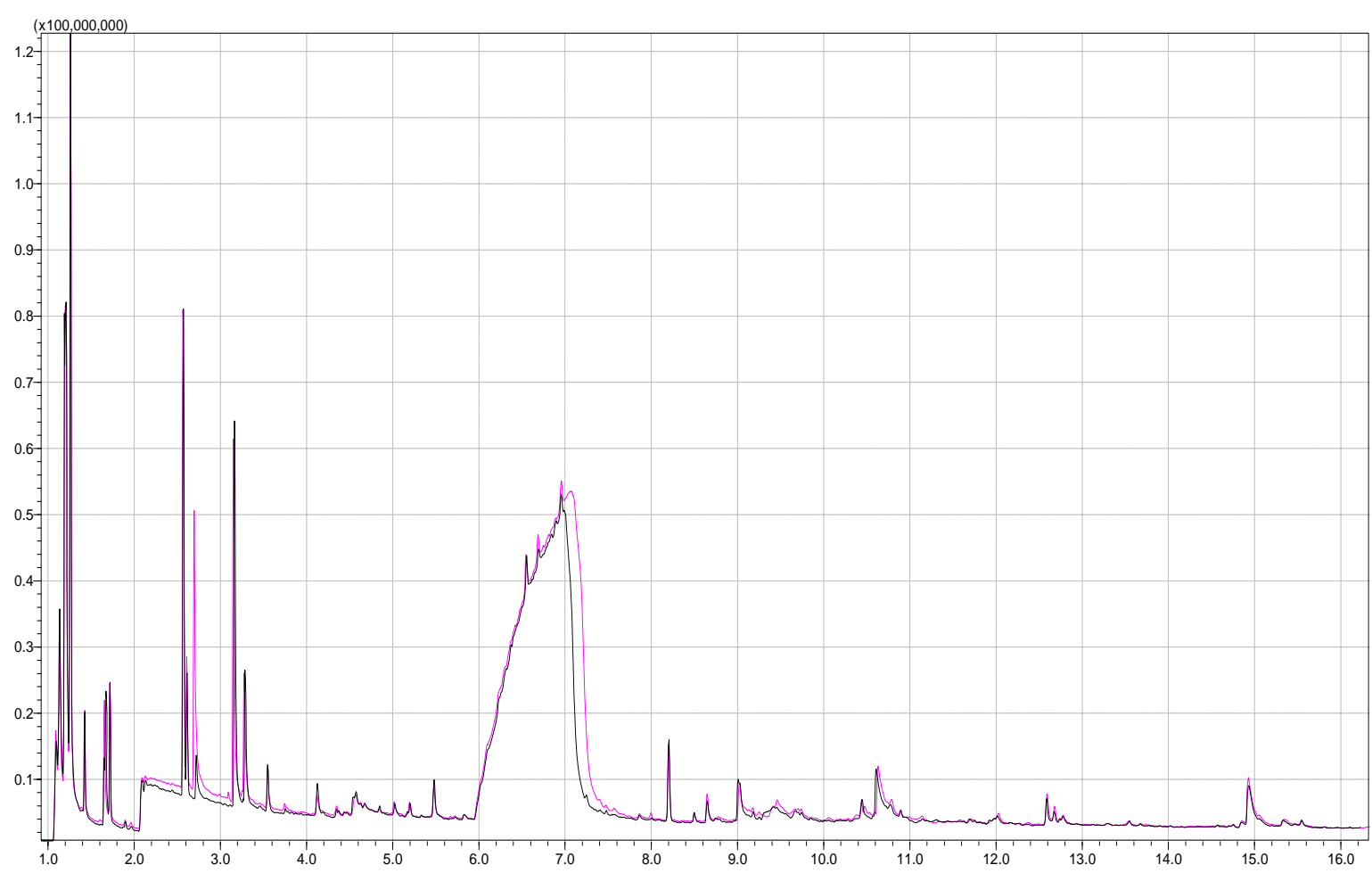

Figure 2. The comparative analysis of the composition of raw material wine (white) and "Muscat" wine using the GC/MS method with the injection of liquid samples directly into the capillary column

The reason of this phenomenon consists in the matrix effect of the majority components of wine - ethanol, organic acids, esters, and, in particular, glycerine, which has an extremely large trace. This fact demonstrates the minor sensibility of the GC/MS method with the injection of liquid samples directly into the capillary column for the analysis of wine components with flavouring potential [11].

The "headspace" method refers to the determination of volatile organic substances in the gaseous phase, which are in equilibrium with those from liquid or solid phase [12]. The sample is thermostated until the establishment of balance of the components which are in gaseous, and respectively liquid or solid phases. The HS mode advantages are:

- The position in agitator allows overlapping analysis of precursor sample and incubation of following samples, respectively

- Sample will be gained only when GC is in ready state

- After injection heated syringe is automatically cleaned by purge gas

- Flexible definition of method parameters

The initial concentration of a component from sample in the field of Henry's law validity is given by equation (1):

$$
C_{O L}=\frac{C_{G}\left(K_{V L}+V_{G}\right)}{V_{L}}
$$

where: $\mathrm{C}_{\mathrm{OL}}-$ is the initial concentration of component in the liquid phase;

$\mathrm{C}_{\mathrm{G}}-$ component concentration in the gaseous phase;

$\mathrm{K}$ - coefficient of gas - liquid reference for a certain component at the analysis temperature;

$\mathrm{V}_{\mathrm{G}}-$ volume of the gaseous phase;

$\mathrm{V}_{\mathrm{L}}-$ volume of the liquid phase.

This technique of introducing the sample is used when the interest components are situated in non-volatile and dirty matrices or that contain large amounts of water. 
The matrix effects can be reduced by saturation of aqueous samples with salt in order to obtain the "salting out" effect, or by saturation of an organic sample with water. The temperature control and reproducibility are essential for obtaining the reproducible results. In case of quantitative determination, the method requires a prior calibration, because the distribution coefficient $\mathrm{K}$ of the equation is not known (1). The method is recommended, especially, for the analysis of volatile pollutants, of the components with flavouring potential from food, beverages and pharmaceutical products.

The differential analysis of the composition of raw material wine and of "variety" wine, made by the administration of "Muscat" naturally identical aromatizer using the GC/MS method with the injection of samples by HS method, demonstrates the presence of some significant differences (figure 3).

In the "Muscat" wine, the presence of a range of monoterpenes $\left(\mathrm{C}_{10} \mathrm{H}_{16}\right)$ is identified: beta-myrcen (2,6,7-octatriene), p-cymen, D-limonen, beta $(\mathrm{Z}, \mathrm{E})$-ocimene and terpineol. All these monoterpenes were identified in grapes of flavoured varieties [13], although these are formed in insignificant amounts and are not of interest in the olfactory field. At the same time, they are part of the composition of essential oils extracted from exotic and flavoured plants: limonen - from lemons and oranges, terpinol - from coriander, myrcenelum - from Myrcia acris plant, ocimenum - from basil leaves, p-cymen - from camphor tree wood. The presence of an insignificant trace, from the point of view of intensity, but identified with certainty (camphor) demonstrates once again that the concerned monoterpenes were not formed in grapes, but come from essential oils extracted from plants (but in any case are not of synthetic origin).
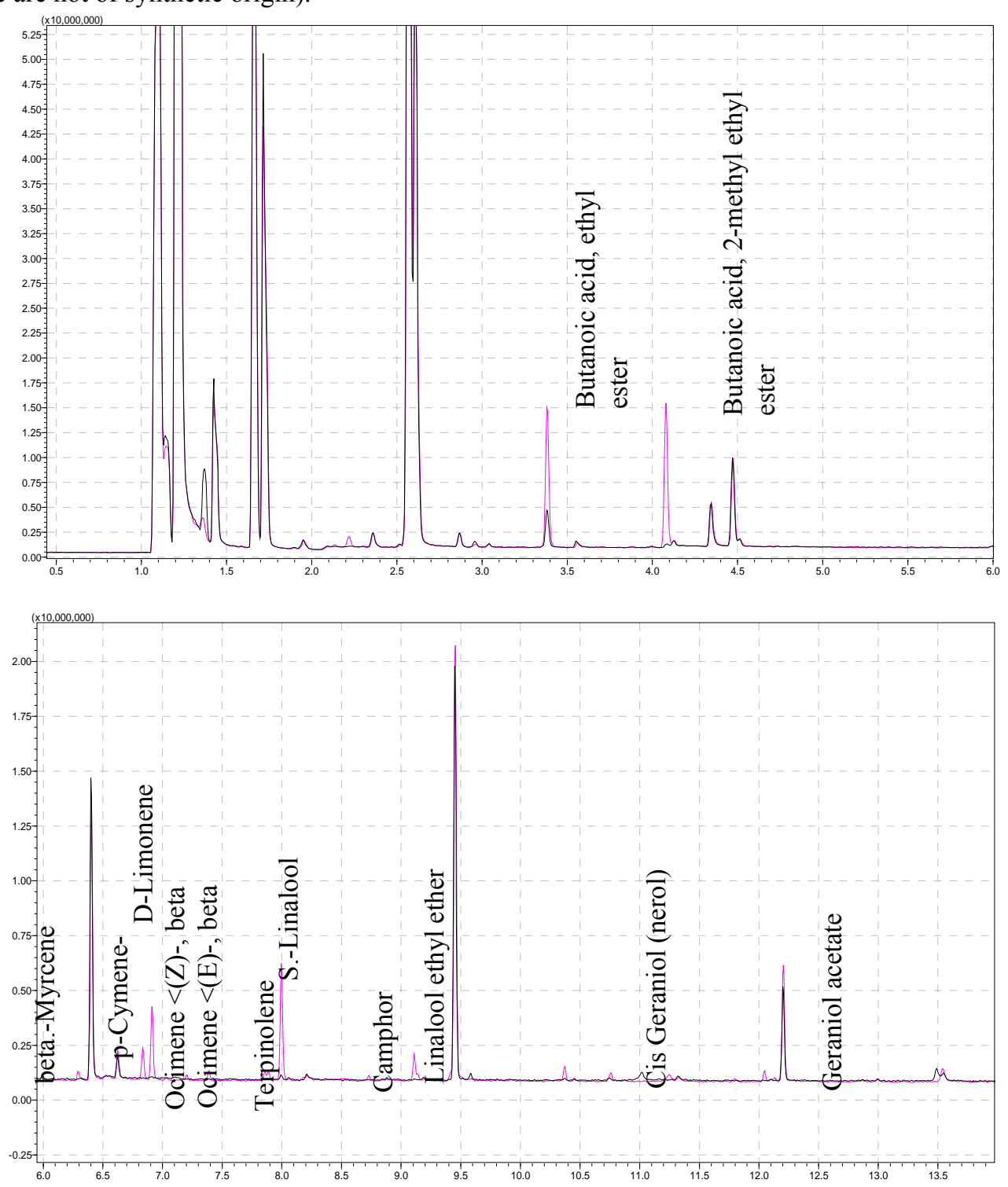

Figure 3. The identification of differences between the composition of raw material wine (white) and "Muscat" wine using the GC/MS method with sample injection by HS method (the identified substances are lacking in the row materials wine 
The terpene monohidroxilic alcohols (terpenols) are the most important compounds with flavouring potential, because these represent volatile free flavours from aromatic grapes. From the quantitative point of view, they represent about $40-50 \%$ of dosed volatile aromatic substances, having a very low threshold of volatile perception, of $0,1-0,5 \mathrm{mg} / \mathrm{L}$ of wine [14]. The main terpenols are linalool, geraniol, nerol, citronelol, hotrienol (HO-trienol, (5E)-3,5-dimethylocta-1,5,7-trien-3-ol) and $\alpha$-terpineol.

In the case of "Muscat" wine, obtained by using the naturally identical aromatizer, the presence of $S$-linalool and of ethyl ester of linalool was identified. The $S$-linalool trace abundance is maximum compared to other compounds with flavouring potential. It is known that namely this tertiary acyclic terpenic alcohol possesses muscatel flavour.

The linalool presence has been identified in the essential oils of many plants (linaloil - a tree in Central America, orange, bergamot, rose, etc.). In the grapes of "Muscat" varieties, the linalool represents $53.4 \%$ of the total of terpenic alcohols, nerol and geraniol, that always accompany the linalool, represent only $17,6-31,8 \%$ [15]. In the examined case, the presence of nerol and geraniol acetate were detected, the abundance of traces being insignificant. This acyclic terpenic alcohol is present in essential oils of rose, lavender, citronel. By oxidation this is converted into aldehyde (geranial), with an odorous impact much weaker than geraniol.

The fatty acids and their volatile esters represent real indicators of the fermentation aroma, which prints the "vinous" character through odorous nuances of fruits. In the raw material wine, an important number of volatile esters of inferior fatty acids with short and medium chain have been found (Table 1).

Table 1

The chemical composition of volatile fraction of raw material wine "Mixture of white European varieties"

\begin{tabular}{|c|c|c|c|c|c|c|}
\hline \multicolumn{7}{|c|}{ Peak Report TIC } \\
\hline Peak\# & R. Time & Area & Area\% & Height & Height $\%$ & $\mathrm{~A} / \mathrm{H}$ Name \\
\hline 1 & 1.369 & 15220650 & 2.37 & 7931129 & 1.98 & 1.92 1-Buten-3-yne, 1-chloro-, (Z)- \\
\hline 2 & 1.425 & 29537686 & 4.59 & 16918729 & 4.22 & 1.75 Propane, 1,2-dimethoxy- \\
\hline 3 & 1.662 & 118982681 & 18.50 & 64613207 & 16.11 & 1.84 1,3-Dioxolane, 2-methyl- \\
\hline 4 & 1.716 & 75116469 & 11.68 & 49678347 & 12.38 & 1.51 o-Allylhydroxylamine \\
\hline 5 & 1.950 & 1510728 & 0.23 & 891844 & 0.22 & 1.69 Cyclopentane, methyl- \\
\hline 6 & 2.359 & 2321591 & 0.36 & 1428268 & 0.36 & 1.63 Propanoic acid, ethyl ester \\
\hline 7 & 2.567 & 220919591 & 34.35 & 133093986 & 33.18 & 1.66 1-Butanol, 3-methyl- \\
\hline 8 & 2.608 & 89391431 & 13.90 & 64739321 & 16.14 & 1.38 1-Butanol, 2-methyl- \\
\hline 9 & 2.868 & 1992157 & 0.31 & 1359676 & 0.34 & 1.47 Propanoic acid, 2-methyl-, ethyl ester \\
\hline 10 & 2.958 & 841221 & 0.13 & 562401 & 0.14 & 1.50 Spiro[2.4]hepta-4,6-diene \\
\hline 11 & 3.041 & 457562 & 0.07 & 333759 & 0.08 & 1.37 Propanoic acid, 2-oxo-, methyl ester \\
\hline 12 & 3.382 & 5310773 & 0.83 & 3724880 & 0.93 & 1.43 Isobutyrate <ethyl-> \\
\hline 13 & 3.552 & 957883 & 0.15 & 611089 & 0.15 & 1.57 Acetic acid, methoxy-, ethyl ester \\
\hline 14 & 4.085 & 563240 & 0.09 & 305472 & 0.08 & 1.84 Butanoic acid, 2-methyl- \\
\hline 15 & 4.126 & 842501 & 0.13 & 570415 & 0.14 & 1.48 Butanoic acid, 3-methyl-, ethyl ester \\
\hline 16 & 4.343 & 6598608 & 1.03 & 4322961 & 1.08 & 1.53 1-Heptene, 2,6-dimethyl- \\
\hline 17 & 4.471 & 12567387 & 1.95 & 8895998 & 2.22 & 1.41 2,3-Pentanedione, 4-methyl- \\
\hline 18 & 6.401 & 18814779 & 2.93 & 13688347 & 3.41 & 1.37 Hexanoic acid, ethyl ester \\
\hline 19 & 6.623 & 1351913 & 0.21 & 929153 & 0.23 & 1.45 Acetic acid, hexyl ester \\
\hline 20 & 7.994 & 259434 & 0.04 & 201309 & 0.05 & 1.29 1,6-Octadien-3-ol, 3,7-dimethyl- \\
\hline 21 & 8.050 & 156101 & 0.02 & 79323 & 0.02 & 1.97 Nonanal \\
\hline 22 & 8.207 & 344769 & 0.05 & 215963 & 0.05 & 1.60 Phenethyl alcohol \\
\hline 23 & 9.450 & 27217854 & 4.23 & 18851410 & 4.70 & 1.44 Octanoate <ethyl-> \\
\hline 24 & 9.584 & 515303 & 0.08 & 286335 & 0.07 & 1.80 Decanal \\
\hline 25 & 12.202 & 6484313 & 1.01 & 4266728 & 1.06 & 1.52 Decanoate < ethyl-> \\
\hline 26 & 14.655 & 186027 & 0.03 & 111184 & 0.03 & 1.67 Phthalate < diethyl-> \\
\hline 27 & 14.708 & 274765 & 0.04 & 206338 & 0.05 & 1.33 Pentanoic acid, 2,2,4-trimethyl-3-carboxyi \\
\hline 28 & 15.543 & 1805999 & 0.28 & 867404 & 0.22 & 2.08 3,5-Diisopropoxy-1,1,1,7,7,7-hexamethyl- \\
\hline 29 & 17.278 & 1503831 & 0.23 & 803174 & 0.20 & 1.87 3-Butoxy-1,1,1,7,7,7-hexamethyl-3,5,5-tri \\
\hline 30 & 17.926 & 1111936 & 0.17 & 669875 & 0.17 & 1.66 Benzamide, N-[2-(1,1,2,3,3,3-hexafluorop \\
\hline & & 643159183 & 100.00 & 401158025 & 100.00 & \\
\hline
\end{tabular}

The differential scanning of the chromatograms of raw material wine and "variety" wine allowed to detect an essential increase of the content of an ester with fruit aromatic notes: ethyl butanoate (pineapple). As well, the presence of 2-ethyl methylbutanoate with apple aromatic nuance was detected (figure 3). These two aromatic compounds, which characterize the wines of "Muscat" type, have an extremely low olfactory perception threshold: 0 , $02 \mathrm{mg} / \mathrm{L}$ for the ethyl butanoate and $1 \mu \mathrm{g} / \mathrm{L}$ for ethyl methylbutyrate. In the raw material wine, the 3-ethyl methylbutanoate is present, but the abundance of this trace is much lower than of its isomers found in wine with "variety" flavour. It is obvious that the presence of these two abundant traces in wine with "variety" flavour cannot 
be attributed to the accumulation of these compounds in grapes, a fact also confirmed by the difference between the two isomers.

The carried out research shows with certainty that the GC/MS technique with sample injection by the "Headspace" method, allows the assessment of qualitative and semi-quantitative composition of the substances with wine flavouring potential even in the absence of respective standards. Meanwhile, the method also allows the detection of residues of contaminants or pollutants - for example, in the raw material wine, the signs of diethylftalat have been found (table 1).

As the purpose of this research was to compare the sensibility of the analytical methods for samples injection in detecting the compounds with wine flavouring potential, the analysis of raw material wine and of "variety" wine with samples injection by the solid phase microextraction (SPME) was carried out. The differential scanning of chromatographic traces for the basic wine and for the "variety" flavoured wine demonstrated the presence of the following compounds (figure 4).
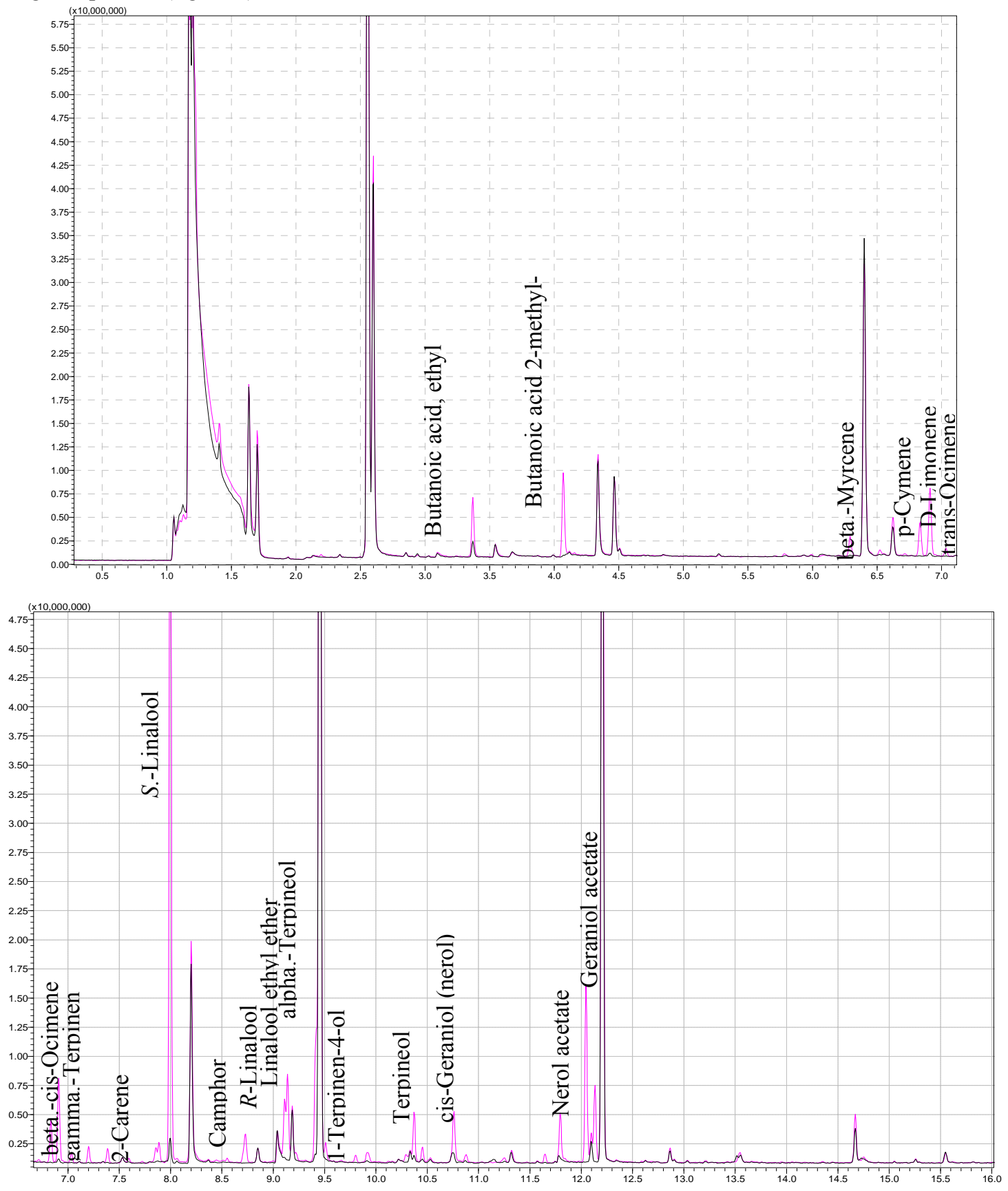

Figure 4. The identification of differences between the composition of raw material wine (white) and "Muscat" wine using the GC/MS method with samples injection by the solid phase microextraction (SPME) 
SPME is a solvent less extraction technique that can be used to extract analytes from both liquid and solid matrices. The quantitative use of this technique has been proven with the automatic robot. The use of SPME for the analysis of flavours and off-flavours in food and beverages is an important preparation tool.

In addition to the compounds detected by the "Headspace" sample injection method, the presence of following monohidroxylic terpenic alcohols was reported: terpineol, alpha-terpineol and 1-terpinen-4-ol. The presence of nerol acetate was also additionally detected. The presence of these compounds with flavouring potential, although in insignificant quantities, demonstrates the natural origin of the used aromatizer (essential oils).

The intensity of chromatographic traces in the case of SPME method is considerably higher (figure 5). Thus, the beta-linalool trace in the case of SPME is saturated. The alpha-terpineol trace, masked in the case of "Headspace" method by the ethyl decanoat trace, a less volatile ester, but present in significant quantities in the raw material wine, is detected in the case of samples injection using the SPME method. The chromatograms comparison for the "variety" wine obtained by these two methods of samples injection indicates that the "Headspace" method, although it can be applied successfully to the analysis of compounds with wine flavouring potential, has certain drawbacks - the vapour phase composition varies essentially from the liquid phase composition. The volatility of components has a predominant role in this case.

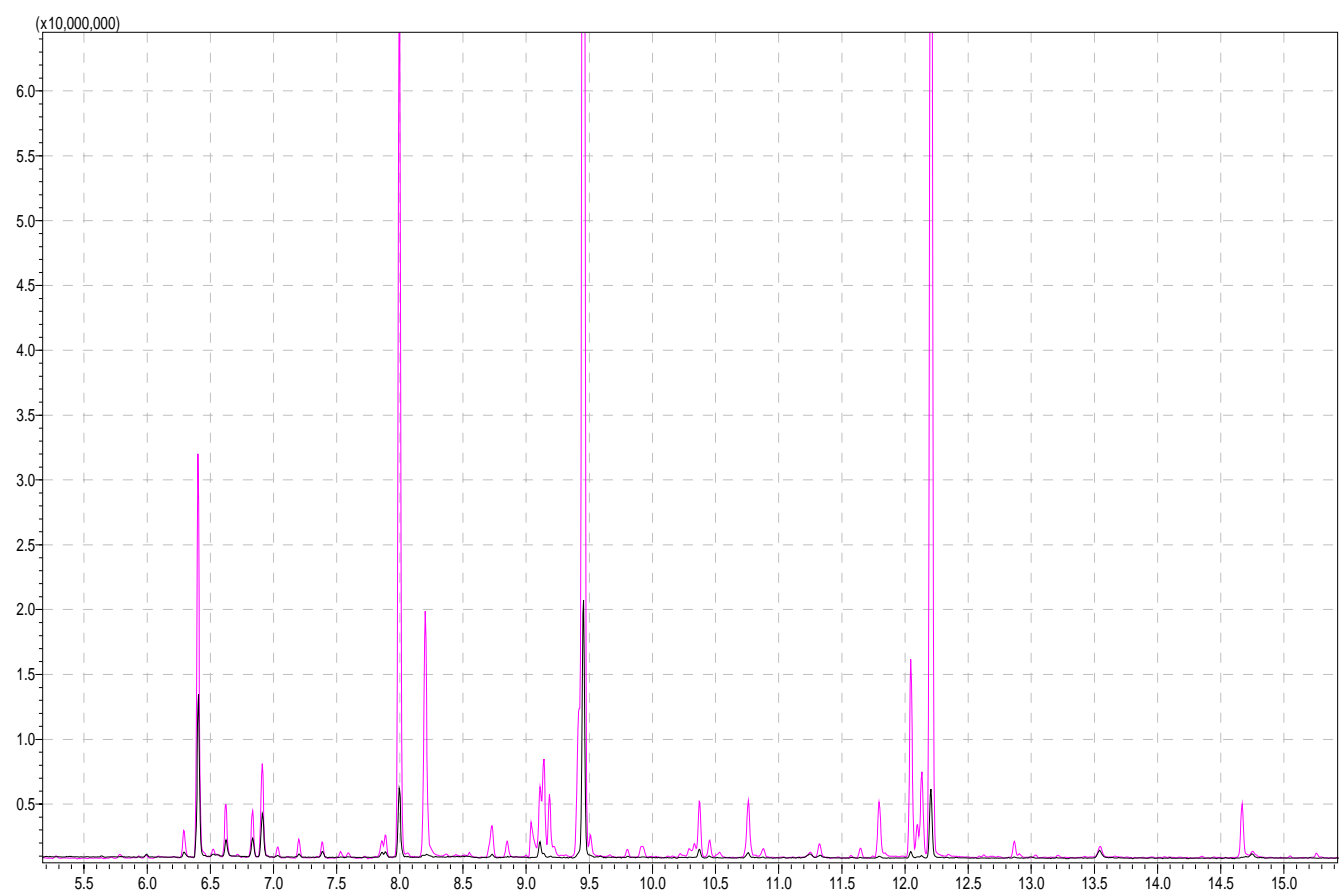

Figure 5. The comparison of the sensibility of the GC/MS method with samples injection by the solid phase microextraction (SPME) (red) and "Headspace" (black)

The sensibility and the resolution of chromatographic separation are considerably higher when the SPME method is applied. The quantity of sample extracted from the solution can be determined by the relationship:

$$
m=\frac{K_{f / s} \cdot V_{f} \cdot C_{o} \cdot V_{s o l}}{K_{f / s} \cdot V_{f}+V_{s o l}},
$$

where: $\quad V_{f}$ and $V_{s}$ are the stationary phase volume and the solution volume;

$K_{f / s}$ - coefficient of distribution of the component at the interface of stationary phase / solution phase;

$\mathrm{C}_{0}-$ initial concentration of component in solution.

The relationship (2) demonstrates the linearity between the component mass absorbed by the organic fibre and its concentration in the solution. Because the organic substances being in the aqueous solution have a higher net affinity towards the organic fibre (in the examined case - carboxen), which has a much less polar character than the aqueous phase, these will be distributed essentially in the organic phase, that is $V_{s o l}>>K_{f / s}$, and the equation (2) becomes:

$$
m=K_{f / s} \cdot V_{f} \cdot C_{o}
$$


Thus, the quantity of sample extracted from the solution to be analyzed is independent of the sample volume, which is an extremely important fact that assures the repeatability and reproducibility of the analysis results.

The testing of raw material wine "Mixture of European red varieties" using the GC/MS method with samples injection through the solid phase microextraction (SPME) has allowed the identification of 60 compounds, these belonging to different classes of substances (table 2).

The chemical composition of raw material wine "Mixture of European red varieties"

Table 2

\begin{tabular}{|c|c|c|c|c|c|c|}
\hline \multicolumn{7}{|c|}{ Peak Report TIC } \\
\hline Peak\# & R.Time & Area & Area $\%$ & Height & Height $\%$ & A/H Name \\
\hline 1 & 1.639 & 44866981 & 6.00 & 30945919 & 6.32 & 1.45 Acetic acid, 1-methylethyl ester \\
\hline 2 & 1.704 & 29377050 & 3.93 & 21375333 & 4.37 & 1.37 Propane, 2-nitro- \\
\hline 3 & 1.940 & 1015107 & 0.14 & 730563 & 0.15 & 1.39 1-Butanol \\
\hline 4 & 2.341 & 960214 & 0.13 & 564456 & 0.12 & 1.70 Propanoic acid, ethyl ester \\
\hline 5 & 2.500 & 1895982 & 0.25 & 1681600 & 0.34 & 1.13 Acetylpropionyl \\
\hline 6 & 2.558 & 168166787 & 22.49 & 113834147 & 23.25 & 1.48 1-Butanol, 3-methyl- \\
\hline 7 & 2.599 & 103284327 & 13.81 & 66062336 & 13.50 & 1.56 Propanoic acid, 2,2-dimethyl-, methyl estes \\
\hline 8 & 2.854 & 2646200 & 0.35 & 1177555 & 0.24 & 2.25 Propanoic acid, 2-methyl-, ethyl ester \\
\hline 9 & 2.905 & 262675 & 0.04 & 201661 & 0.04 & 1.30 Butane, 1-(ethenyloxy)-3-methyl- \\
\hline 10 & 2.944 & 1449636 & 0.19 & 1067057 & 0.22 & 1.36 Spiro[2.4]hepta-4,6-diene \\
\hline 11 & 3.028 & 323650 & 0.04 & 245888 & 0.05 & 1.32 Acetic acid, 2-methylpropyl ester \\
\hline 12 & 3.085 & 9380493 & 1.25 & 3417608 & 0.70 & 2.74 2,3-Butanediol, [R-(R*, $\left.\left.\mathrm{R}^{*}\right)\right]-$ \\
\hline 13 & 3.227 & 2304773 & 0.31 & 600036 & 0.12 & 3.84 2,3-Butanediol \\
\hline 14 & 3.373 & 1867274 & 0.25 & 1307942 & 0.27 & 1.43 Isobutyrate <ethyl-> \\
\hline 15 & 3.545 & 6657408 & 0.89 & 3799158 & 0.78 & 1.75 Acetic acid, methoxy-, ethyl ester \\
\hline 16 & 3.705 & 413943 & 0.06 & 314100 & 0.06 & 1.32 1,3-Butadiene, 1,4-dimethoxy-, (Z,Z)- \\
\hline 17 & 3.874 & 306601 & 0.04 & 218463 & 0.04 & 1.40 1-Pentanol, 4-methyl- \\
\hline 18 & 3.995 & 668372 & 0.09 & 454231 & 0.09 & 1.47 1-Pentanol, 3-methyl- \\
\hline 19 & 4.075 & 524624 & 0.07 & 384810 & 0.08 & 1.36 Butanoic acid, 2-methyl- \\
\hline 20 & 4.120 & 1182375 & 0.16 & 777910 & 0.16 & 1.52 Butanoic acid, 3-methyl-, ethyl ester \\
\hline 21 & 4.342 & 12479103 & 1.67 & 7605333 & 1.55 & 1.64 1-Heptene, 2,6-dimethyl- \\
\hline 22 & 4.468 & 13566349 & 1.81 & 9941119 & 2.03 & 1.36 2,3-Pentanedione, 4-methyl- \\
\hline 23 & 4.727 & 226118 & 0.03 & 154789 & 0.03 & 1.46 Benzene <ethyl-> \\
\hline 24 & 5.936 & 703016 & 0.09 & 430731 & 0.09 & 1.63 2-Octene, 3,7-dimethyl-, (Z)- \\
\hline 25 & 5.998 & 561120 & 0.08 & 287825 & 0.06 & $1.95 \mathrm{~N}$-Acetylisoxazolidine \\
\hline 26 & 6.062 & 1576702 & 0.21 & 552331 & 0.11 & 2.85 Ethanol, 2,2-diethoxy- \\
\hline 27 & 6.207 & 686573 & 0.09 & 199286 & 0.04 & 3.45 Ethane, 1,1,1-triethoxy- \\
\hline 28 & 6.403 & 33096736 & 4.43 & 22726267 & 4.64 & 1.46 Hexanoic acid, ethyl ester \\
\hline 29 & 6.627 & 333807 & 0.04 & 250597 & 0.05 & 1.33 Acetic acid, hexyl ester \\
\hline 30 & 7.534 & 1043067 & 0.14 & 560141 & 0.11 & $1.861-$-Octanol \\
\hline 31 & 7.961 & 522462 & 0.07 & 368118 & 0.08 & 1.42 Heptanoic acid, ethyl ester \\
\hline 32 & 8.000 & 439696 & 0.06 & 346271 & 0.07 & 1.27 1,6-Octadien-3-ol, 3,7-dimethyl- \\
\hline 33 & 8.202 & 67685812 & 9.05 & 39032807 & 7.97 & 1.73 Phenethyl alcohol \\
\hline 34 & 8.370 & 589534 & 0.08 & 320902 & 0.07 & 1.84 Octanoate $<$ methyl- $>$ \\
\hline 35 & 8.851 & 1935948 & 0.26 & 1128687 & 0.23 & 1.72 Heptanal < cyclic-, ethylene- $>$ acetal \\
\hline 36 & 9.072 & 1786362 & 0.24 & 873580 & 0.18 & 2.04 1-Nonanol \\
\hline 37 & 9.186 & 8422817 & 1.13 & 5628783 & 1.15 & 1.50 Succinate $<$ diethyl- $>$ \\
\hline 38 & 9.455 & 145228511 & 19.42 & 99505411 & 20.33 & 1.46 Octanoate <ethyl- $>$ \\
\hline 39 & 10.223 & 729368 & 0.10 & 267367 & 0.05 & 2.73 Hexanoate <isopentyl- $>$ \\
\hline 40 & 10.336 & 937456 & 0.13 & 532431 & 0.11 & 1.76 Phenethyl acetate $<2->$ \\
\hline 41 & 10.531 & 606487 & 0.08 & 301959 & 0.06 & 2.01 Decyl alcohol \\
\hline 42 & 10.742 & 2875592 & 0.38 & 1728550 & 0.35 & 1.66 Isoaromadendrene epoxide \\
\hline 43 & 10.869 & 896156 & 0.12 & 684897 & 0.14 & 1.31 Nonanoate $<$ ethyl- $>$ \\
\hline 44 & 11.248 & 674000 & 0.09 & 321817 & 0.07 & 2.09 1,3-Dioxolane, 2-(5-bromopentyl)- \\
\hline 45 & 11.319 & 1522606 & 0.20 & 776612 & 0.16 & 1.96 Hexasiloxane, $1,1,3,3,5,5,7,7,9,9,11,11$-do \\
\hline 46 & 12.099 & 1044406 & 0.14 & 644610 & 0.13 & 1.62 4-Decenoic acid, ethyl ester, (Z)- \\
\hline 47 & 12.206 & 52638024 & 7.04 & 35256483 & 7.20 & 1.49 Decanoate <ethyl-> \\
\hline 48 & 12.628 & 192135 & 0.03 & 171167 & 0.03 & 1.12 Hexanedioic acid, bis(1-methylethyl) ester \\
\hline 49 & 12.866 & 738451 & 0.10 & 459589 & 0.09 & 1.61 Octanoate $<$ isopentyl- $>$ \\
\hline 50 & 13.211 & 377891 & 0.05 & 239501 & 0.05 & 1.58 Pentafluoropropionic acid, tridecyl ester \\
\hline 51 & 13.546 & 1923562 & 0.26 & 771944 & 0.16 & 2.49 2-Propenoic acid, 2,3,3-tris[(trimethylsilyl) \\
\hline 52 & 14.670 & 6239169 & 0.83 & 3865254 & 0.79 & 1.61 Dodecanoate <ethyl-> \\
\hline 53 & 14.756 & 2044330 & 0.27 & 975819 & 0.20 & 2.09 Propanoic acid, 2-methyl-, 1-(1,1-dimethyl \\
\hline 54 & 15.261 & 280038 & 0.04 & 227353 & 0.05 & 1.23 Sulfurous acid, dipentyl ester \\
\hline 55 & 15.550 & 1421638 & 0.19 & 792088 & 0.16 & 1.79 D-Arabinonic acid, 2,3,5-tris-O-(trimethyls \\
\hline 56 & 16.895 & 545695 & 0.07 & 320225 & 0.07 & 1.70 Tetradecanoic acid, ethyl ester \\
\hline 57 & 17.282 & 1221285 & 0.16 & 666669 & 0.14 & 1.83 3-Butoxy-1,1,1,7,7,7-hexamethyl-3,5,5-tris \\
\hline 58 & 17.699 & 521151 & 0.07 & 315682 & 0.06 & 1.65 1,2-Benzenedicarboxylic acid, dipropyl est \\
\hline 59 & 18.641 & 530401 & 0.07 & 333600 & 0.07 & 1.59 1,2-Benzenedicarboxylic acid, bis(2-methy \\
\hline 60 & 18.912 & 1326010 & 0.18 & 789269 & 0.16 & 1.68 Ethyl hydrogen dodecanedioate \\
\hline & & 747724056 & 100.00 & 489516637 & 100.00 & \\
\hline
\end{tabular}


The differential scanning of chromatograms of the raw material wine and of the Izabela "variety" wine, obtained by the administration of "naturally identical" aromatizer (according to commercial features) demonstrated the presence of the following traces (figure 6). The presence of methylanthranilat is attested - a component of the primary flavours of American hybrid grapes. The abundance of this trace is prevalent among the registered flavouring components.
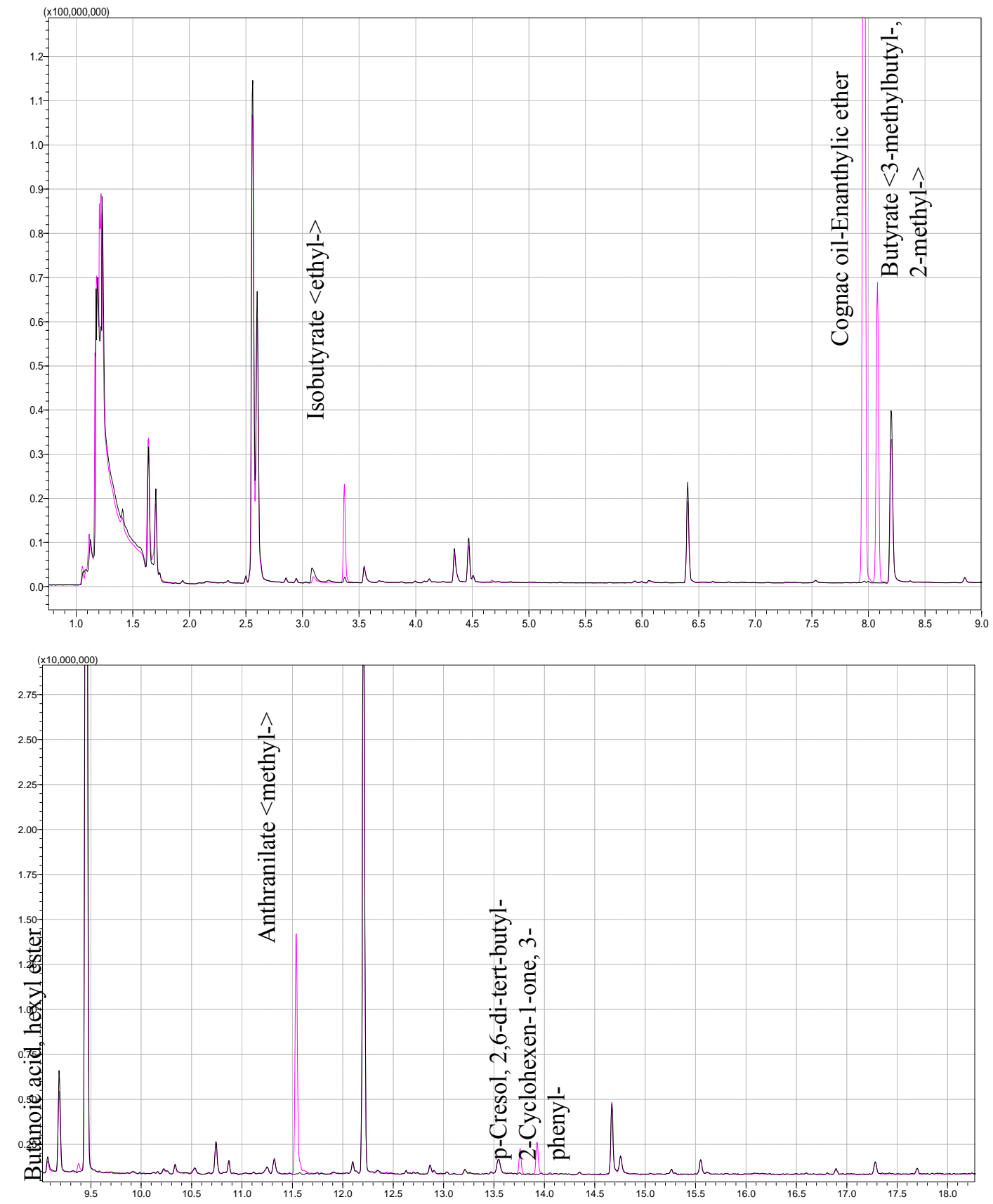

Figure 6. The identification of the differences between the composition of raw material wine (red) and "Izabela" wine using GC/MS method with samples injection by the solid phase microextraction (SPME)

The ethyl izobutirat was found, an ester with a nuance of fruit and fusel flavour, which is characteristic for the wines of Muscatel type, with a very low threshold of olfactory perception - $0.02 \mathrm{mg} / \mathrm{L}$. Its presence in the composition of flavouring substances is not characteristic for the wines of Vitis Labrusca varieties. As well, two significant traces of enantilic and butyrate ether $<3$-methylbutil, 2-methyl- $>$ were recorded - two chemicals of synthetic origin with pineapple flavour (enantilic ether) and fruit caramel (butyrate $<3$-metilbutil-, 2-methyl- $>$ ). The hexilic ester of the butanoic acid, present in extremely low quantity (pineapple flavour) can be of synthetic origin, but is also detected in the composition of natural wines [16]. 
The presence of the p-Cresol, 2,6-di-tert-butyl- compound, an antioxidant agent of synthetic origin, restricted to food products, demonstrates eloquently the synthetic origin of the concerned aromatizer. This compound, which manifests allergic effect and is suspected to be carcinogenic, is not part of the flavouring compounds, but is included in the composition of the synthetic aromatizer for its antioxidant effect.

3 - phenyl-2-cyclohexene-1-ona also represents a synthetic compound that could be used as a solvent for $p$ Cresol, 2,6-di-tert-butyl.

The carried out research demonstrated that the usage of the GC/MS method with sample injection by "Headspace" method and with the solid phase microextraction (SPME) can be successfully applied to identify the aromatic profile of wines, to detect the wine counterfeiting (by using naturally identical and synthetic aromatizers). It is also relatively easy to detect the origin of the aromatizer. In the case of the naturally identical, the presence of a greater number of traces, characteristic for substances with flavouring potential, is detected. For the synthetic aromatizers, the number of components with flavouring potential is lower (for the "Izabela" aromatizer, only 5 compounds with flavouring potential have been found), but there were recorded two chemicals which have nothing in common with the flavouring substances, but fulfil various functions.

The sensitivity of the method decreases in the order to use the following analytical techniques for samples injection:

\section{SPME $>$ „Headspace” >> injection of liquid samples directly into the capillary column}

The GC/MS method with the injection of liquid samples directly into the capillary column can not be applied to identify the aromatic profile of wines, as in this case the effect of the matrix leads to the decrease of sensibility in the detection of substances that are present in very small quantities. The GC/MS method with the samples injection by the solid phase microextraction provides a higher sensibility than the method of samples injection by application of the "Headspace" technique.

\section{References}

[1]. Natera R, Castro R, Morena MVG, Hernandez MJ, Barroso CG (2003) Agric Food Chem 51: 3345-3351.

[2]. Morales ML, Gonzales GA, Casas JA, Troncoso AM (2001) Eur Food ResTechnol 212 : 676-682

[3]. Flanzy C., Enologie, fondements scientifiques et technologiques", Londre, Paris, New York, Technique \& Documentation, 1998.

[4]. Favretto D, Grandis G, Allegri G, Traldi P (1998) Rapid Commun Mass Spectrom 12 :1595-1600.

[5]. Bonino M, Schellino R, Rizzi C, Aigotti R, Delfini C, Baiocchi C (2003) Food Chem 80 : 125-133.

[6]. Riberau-Gayon P., „Les composées phénoliques des végétaux”, Dunod, Paris, 1998, pp.410.

[7]. Sirghi.C, Zironi R., „Aspecte inovative ale enologiei moderne”, Editura "Sigma”, Chişinău, 1994.

[8]. Gholami M., Hayasaka Y., Coombe B.G., Jackson J.F., Robinson S.P., Williams P.J. Biosynthesis of flavour compounds in Muscat Gordo Blanco grape berries. Australian Journal of Grape and Wine Research. Volume 1 Issue 1, pp. 19 - 24. Published Online: 12 Mar 2008

[9]. Institutul Naţional pentru Viticultură şi Vinificație din Republica Moldova „,Realizări inovative în domeniul Viti-vinicol”, Ediție specială a Conferinței Internaționale consacrate comemorării mc. AŞM Petru Ungureanu, 18-19 septembrie, 2008, Chişinău.

[10]. Mohamed A., Menno B., Hans-Ulrich B., Rene J.J. Vreuls, Brinckman Udo A.TH., Comprehensive TwoDimensional Gas Chromatography coupled to rapid-scanning Quadrupole Mass Spectrometer (GC $\times \mathrm{GC}-\mathrm{qMS})$ : Principles and Applications. Journal of Chromatography A, Volume 1067, Issues 1-2, 4 March 2005, pp. 245-254.

[11]. Van Wyk C. J., Dinsmoor W., Kepner R. E., Some Volatile Components of Vitis Vinifera Variety White Riesling 1, Grape Juice. Journal of Food Science, Volume 32 Issue 6, 2006, pp. 660 - 664.

[12]. Gocan S., “ Cromatografia de inaltă performanță” Partea 1., Cromatografia de gaze. Ed. Dacia, Cluj-Napoca, 1998.

[13]. Sanchez-Palomo E., Diaz-Maroto C., "Rapid determination of volatile compounds in grapes by HS-SPME coupled with GC-MS", Talanta, Volume 66, Issue 5, 15 June 2005, pp. 1152-1157.

[14]. Rosillo L., Salinas M.R., Garijo J., Alonso G.L., "Study of volatiles in grapes by dynamic headspace analysis Application to the differentiation of some Vitis vinifera varieties". Journal of Chromatography A, Volume 847, Number 1, 25 June 1999 , pp. 155-159(5).

[15]. Țirdea C., “ Chimia şi analiza vinului”, Editura „Ion Ionescu de la Brad”, Iaşi, 2007.

[16]. Analysis of Grape Volatiles by Solid Phase Microextraction and Comprehensive Two-Dimensional Gas Chromatography with Time-of-Flight Mass Spectrometry (GCxGC-TOFMS). Form No. 203-821-270 3/08REV (C2008 LECO Corporation MI 49085]. 